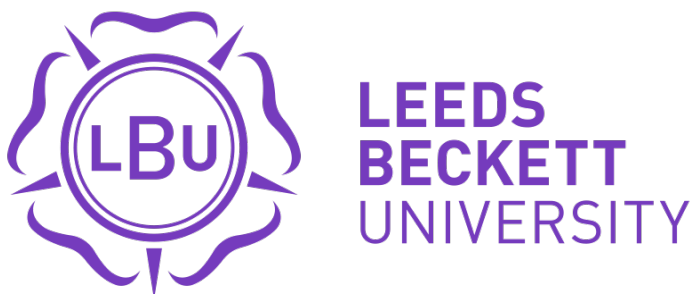

Citation:

Burrai, E and Font, X and Cochrane, J (2014) Destination Stakeholders' Perceptions of Volunteer Tourism: An Equity Theory Approach. International Journal of Tourism Research, 17 (5). 451 - 459. ISSN 1099-2340 DOI: https://doi.org/10.1002/jtr.2012

Link to Leeds Beckett Repository record:

https://eprints.leedsbeckett.ac.uk/id/eprint/105/

Document Version:

Article (Updated Version)

The aim of the Leeds Beckett Repository is to provide open access to our research, as required by funder policies and permitted by publishers and copyright law.

The Leeds Beckett repository holds a wide range of publications, each of which has been checked for copyright and the relevant embargo period has been applied by the Research Services team.

We operate on a standard take-down policy. If you are the author or publisher of an output and you would like it removed from the repository, please contact us and we will investigate on a case-by-case basis.

Each thesis in the repository has been cleared where necessary by the author for third party copyright. If you would like a thesis to be removed from the repository or believe there is an issue with copyright, please contact us on openaccess@leedsbeckett.ac.uk and we will investigate on a case-by-case basis. 


\title{
Destination stakeholders' perceptions of volunteer tourism: an equity theory approach
}

Elisa Burrai, Xavier Font and Janet Cochrane

\begin{abstract}
This study explores destination stakeholders' perceptions of volunteer tourism (VT) using equity theory (ET). 26 semi-structured interviews were conducted to understand individuals' needs, motivations, expectations and their assessments of inputs and outcomes. ET sheds light on the microlevel of interaction between residents and volunteers and demonstrates why and how residents of Cusco (Peru) who have an active role in VT develop certain perceptions in direct encounters with volunteer tourists. The data reveals how perceptions differ according to the respondents' social roles within VT. Heterogeneity, dynamism and a fluctuation between materialities and affection are discussed as important outcomes of these interactions.
\end{abstract}

Keywords: Volunteer tourism; residents’ perceptions; social impacts of tourism; equity theory

\section{Introduction}

This study explores the interactions between three groups of destination stakeholders and volunteer tourists. The literature has focused on volunteer tourists' motivations (Brown, 2005; Callanan and Thomas, 2005; Chen and Chen, 2011, Tomazos and Butler, 2010) and transformation through the VT experience (Higgins-Desbiolles and Russell-Mundine, 2008; McGehee and Santos, 2005). Given the paucity of VT studies on destination stakeholders or residents' perceptions and the lack of cohesive theoretical approaches, the present study seeks to shed light on three stakeholder groups' perceptions as the core part of a complex field. This paper, hence, aims to build an understanding of the social aspects of VT through a revisited theorisation of tourist encounters.

We re-examine VT host-guest interactions applying ET, a socio-psychological theory elaborated by Adams in 1963. The theory has the potential to be useful not only to explore individuals' interactions in the context of philanthropic encounters but also to understand how some destination stakeholders perceive volunteers and why they develop certain perceptions. In addition, ET provides the authors with a systematic tool to simplify the complexity of VT.

This paper focuses on perceptions at the micro-level of interaction between key stakeholder groups and volunteer tourists to understand the donor- recipient relationship (i.e. volunteer tourist-resident). The findings of this study highlight the dynamism of VT encounters which develop and transform in 
hybrid spaces. Here "materialities and mobilities" (Hannam et al., 2006:14) meet and allow the economic, cultural and social characteristics of a place to create an affective dimension of the encounters (Crouch, 2000). Therefore, the dynamic and "transformative potential” (Crouch and Desforges, 2003) of individuals' negotiations, interactions and behaviours are highlighted, bearing in mind that individuals' actions and perceptions are generated in relation to the socio-cultural environments they inhabit.

\section{Volunteer tourism}

VT grew significantly in the first decade of the $21^{\text {st }}$ century, gaining the definition of a "mass niche" form of tourism (Callanan and Thomas, 2005). Much of the early literature focused on its benefits, highlighting the personal development of volunteers (Lepp, 2008; McIntosh and Zahra, 2007; Wearing, 2001), better cross-cultural understanding between societies and people (Raymond and Hall, 2008), improved living conditions for the host populations (Wearing, 2001) and increased involvement in social movements and activism (McGehee, 2002; McGehee and Norman, 2002; McGehee and Santos, 2005).

Among the positive features of VT, scholars also underlined the altruism of volunteers and their desire to 'give something back' (Brown 2005; Callan and Thomas, 2005; McIntosh and Zahra, 2007). Accordingly, VT has the potential to "generate the impulse to put something back, to give back to the people and places visitors have encountered" (Goodwin, 2011:183). The main recipients of VT 'giving back' are the residents of developing countries. This same concept of devoting time and money for 'good causes' has been revisited more critically in recent studies. Hence, "after the initial flurry of advocacy-based research” (Wearing and McGehee, 2013: 122), VT has been reconsidered as a form of new colonialism, where the interests and motivations of Western volunteers outweigh the needs and desires of the local residents (Higgins-Desbiolles and Russell-Mundine, 2008, Guttentag, 2009). Some see a potential for VT dependency of hosting countries on volunteer sending nations (Guttentag, 2009; McGehee and Andereck, 2009; Simpson, 2004). Additionally, VT has been seen as a tool to reinforce the "authoritative position of power" of travellers leaving the residents disempowered and marginalised (Sin, 2010: 988).

Given that only a few studies have focused on the residents (Guttentag, 2009; McGehee and Andereck, 2009; McGehee, 2012), this paper seeks to build an understanding of key stakeholder groups' perceptions in a popular VT destination. The groups of residents involved in this study are directly involved and have an active role in VT and we therefore refer to them throughout the paper as destination stakeholders.

The study examines encounters between individuals in social projects (educational and medical centres, shelter houses, orphanages, etc). The choice of focusing on social projects relates to the 
setting where the research was developed. In Cusco (Peru), social projects exist, according to residents, because of poor governmental social assistance, a deficient educational system and widespread societal problems (e.g. alcoholism and domestic violence). Within this problematic scenario, VT quickly grew through the creation of social projects where the presence of volunteers and of commercial (and non-commercial) bodies mixed. Cusco is highly ranked not only for the number of social projects and volunteer opportunities but also because it is a popular tourist destination. It is situated in the highlands of south-east Peru and it is the gateway to the Inca city of Machu Picchu. Tourism developed here based on the historical past of this Andean city, which is the main commercial strength. At the same time, a combination of leisure and philanthropic elements create the perfect environment to set and package a volunteer experience.

\section{Equity theory}

ET helps explain the dynamics in the encounters between stakeholders and tourists. Its application facilitates a deeper understanding of philanthropic relationships and helps to interpret residents' behaviours in their exchanges with volunteer tourists. If individuals perceive there is equity and justice within the exchange relationships they are involved in, they experience feelings of contentment which result in positive reactions and perceptions. ET is presented in terms of inputs and outcomes. An actor invests in a situation which involves the presence of another actor who, at the same time, invests their own resources and also expects certain outcomes. Each actor expects some level of fairness and equity from the exchange, otherwise the relationship will be considered unbalanced (Pearce and Coghlan, 2008). In order to apply ET we assess the inputs that participants perceive they, as well as their counterparts, are contributing and how much (either materially or symbolically) they are getting (or perceiving to get) in return from the interactions.

When equity is not perceived, "there is a desire whether conscious or subconscious to take remedial action to make the situation more equitable” (Emberson, 2002:29). The model acknowledges differences between individuals in constructing and evaluating the meaning of rewards (Pearce et al., 1991). It is also accepted that they use different comparators and that "they will not have the expectations of homogeneity of input” (Emberson, 2002:29). ET postulates that individuals in the encounters try to maximise the positive outcomes for themselves, while if they perceive to be in inequitable relationships, they experience distress. The more inequitable the relationship, the more distress individuals feel (Coghlan, 2005), and the more distress they feel, the harder they may try to restore equity (Walster, Berscheid and Walster, 1973). However parties involved in unfair exchanges may be more inclined to tolerate the on-going inequity assuming that "something is better than nothing” (ibid.:119). Although the model has been widely applied to financial contexts (e.g. employees' satisfaction in workplaces), other research focused on exchanges in dating couples and 
equity assessment in intimate relationships (Hatfield et al., 1979). This avenue of research proved to be particularly relevant in examining the development of affection and care in VT.

Friction between donors and recipients is likely to emerge in unbalanced relationships. An example would be volunteers who may get involved in volunteering abroad to feel good by 'giving something meaningful' back to society. Other reasons are to improve future career prospects, experiencing (or aestheticizing) poverty as authentic and cultural, or - at worst - to take advantage of lower levels of enforcement of human rights in order to culturally exploit local people through Western representations of poverty(Broad, 2003; Halpenny and Caissie, 2003; Mostafanezhad, 2013; Simpson, 2004; Wearing and Deane, 2003; Sin, 2009). Within the ET framework, such reasons are perceived to be low inputs when compared to those invested by some residents.

\section{Methods}

This study used a qualitative interpretative approach to uncover the meanings behind narratives. We adopt ET to identify and analyse the perceptions, behaviours and dynamics of stakeholdervolunteer interactions. Since 1963 the model has been extensively used in socio-psychological studies, while only three tourism studies have applied it. Pearce et al. (1991) focused on the social impacts of tourism; Chang (2008) explored the causal relationships between consumption behaviour and the consequences of tourists' satisfaction; and Coghlan (2005) focused on how the interaction between volunteers and sending organisations shaped volunteers' experiences. Methodologically, all three studies developed their research differently. While Pearce et al. (1991) relied on a quantitative approach, Chang (2008) adopted qualitative methods to analyse the participants' attitudes, feelings and behaviours, and Coghlan (2005) used mixed methods to assess the respondents' (perceived) inputs and outcomes.

We adopt a qualitative approach because it permits an in depth exploration of individual perceptions and behaviours. This is because perceptions of fairness are subjective and differ according to personal values and socio-cultural backgrounds (Chang, 2008). Thus the qualitative application of ET uncovered the subjective ways of making sense of the dynamics which underpin interactions with the volunteers. Needs, motivations and expectations inputs and outcomes are examined in depth without the use of preconceived categories developed a priori through quantitative methods. The qualitative application of ET allows flexibility in approaching the individuals' responses, particularly in identifying and describing their perceptions. An example is found in the ways different stakeholders explain their distress or contentment in relation to their exchanges with volunteers.

The conceptualisation of perceptions is often difficult and interviews facilitate this process. Hence, for example, instead of providing the informants with "mood adjective check lists" (Coghlan, 2005: 36) through which they could rate their level of frustration or happiness, we value the importance of 
subjectively identifying different perceptions and individually elaborating why they occurred. By contextualising perceptions, stakeholders can better explain why certain reactions and relationships emerge and develop.

For this study, ET was applied in three stages. First, the authors assessed individuals' perceptions and behaviours (i.e. balanced or imbalanced exchanges) through the stakeholders' responses. Second, the reasons why these behaviours occur were identified. Frustration derived from inequity is crucial in motivating individuals to reduce or eliminate any relational inequity. The third step explains the stakeholders' reactions to the perceived fairness or inequity in their exchanges with volunteers. The informants' attempts at equity restoration, or equity control, disclose the main (perceived) social impacts. 
*** insert Figure 1 here $* * *$

A schematic representation of the application of ET to this study is given in figure 1. ET postulates that individuals involved in an exchange invest their inputs, defined by needs and motivations, in accordance with their desired outcomes (or expectations) and the investments of their counterparts. Thus, in operationalising ET, the needs, motivations and expectations of informants are assessed and secondly, the inputs and outcomes are evaluated.

One of the researchers volunteered in two different projects: a shelter house for teenage mothers and an after-school project, which provided direct or indirect access to interviewees. Because of the difficulties experienced in knowing the entire accessible population, the respondents were segmented within the sample achieved, which was obtained by a combination of purposive and snowballing sampling techniques. Accessibility dictated that of the 26 stakeholders selected over six months in the field, six were project directors, 16 were members of staff (of whom seven had been beneficiaries in the past) and four were beneficiaries. The names of the informants have been changed for anonymity reasons. To facilitate the analysis, all Directors' names start with D, Members of staff names start with $\mathrm{M}$ and Beneficiaries' names start with B. Additionally, the names of some members of staff who were beneficiaries in the past start with B (i.e. Belinda; Bianca).

The informants were connected with a range of projects as well as the two where the researcher volunteered. The research focused on these three social groups of stakeholders according to their roles in VT. This is because the socio-economic role of the informants is a key factor in shaping their perceptions towards VT for two main reasons. First, their role indicates whether they are directly connected to the financial side of VT (e.g. directors) or not (beneficiaries; members of staff). Perceptions are different if there is a positive/negative financial outcome derived from being involved in the industry (McGehee and Andereck, 2009). Secondly, the different roles of informants and, thus, their different levels of involvement in VT also suggest that people have different motivations, expectations and needs. These differences explain the many different ways in which individuals understand and relate to the phenomenon.

Interviews were held in Spanish, they were audio-recorded and usually conducted in places familiar to the interviewees such as their own homes or projects, while others were interviewed in public places such as cafes, bars and restaurants. All the interviews were transcribed verbatim, however only the quoted passages have been translated from Spanish into English. The analysis of the data followed a manual coding approach allowing the identification of key-words or short sentences which represented units of meaning. Codes were distinguished using different colours according to the thematic section they belonged to (needs, motivations and expectations or inputs and outcomes). 
The emergent patterns of the coding process and the categories, subcategories and themes identified were organised in analytic memos (Saldaña, 2009) which helped to reflect on the choices of the codes, on the emergent patterns, concepts and themes and on the connections among them.

In this study, rigour and credibility are achieved through the use of prolonged engagement with the informants, during which semi-structured interviews were conducted and field notes were taken. Trustworthiness of the findings is reached through the researcher's observation and triangulation of the data (Lincoln and Guba, 1985). Whilst the first leads to familiarisation of the context in "learning the culture, testing the misinformation introduced by distortions either of the self or of the respondents, and building trust” (Lincoln and Guba, 1985:301), triangulation confirms the credibility of the investigation as multiple research techniques are employed.

\section{Results}

The results are structured in two sections. The first focuses on the stakeholders' needs, motivations and expectations as necessary premises for the application of ET to the data. In the second section we examine the perceptions of the same stakeholders of their own inputs and outcomes in comparison to those invested and gained by the volunteer tourists.

\section{Needs}

Individuals' conceptualisation of needs, motivations and expectations were complex and differed across the three groups according to their socio-economic roles. Directors of projects mentioned bigger picture needs, while the closer we got to the beneficiaries, the more needs became personspecific. Directors explained their needs as collective social necessities, mostly quoting social problems such as home violence, negligence resulting in physical and moral abandonment of children, poor educational systems and inadequate social support from the government. For example, Daniel comments that:

"Every day more than ten violent abuses to women and children are reported. And these are only the reported ones. We are the second city in all Peru for levels of domestic violence. We are one of the worse cities for alcohol consumption among youngsters...”.

Also Dalmiro highlights the poor level of education and lack of values among local families:

"Their [children] mothers and fathers are absent [...] so the kids are abandoned, sometimes because of the lack of family structure which clearly reflects the economic and social crisis that now exists”.

The concern for social justice of Daniel and Dalmiro explains the necessity for volunteer tourists in their projects who offer financial or material support. A narrower view of needs is held by members 
of staff, who construct their meanings in relation to the context of the project where they work and are generally more utilitarian: they need help to share their tasks because they claim to have too much work. Belinda says, for example:

"when they [the volunteers] come they can help in the kitchen and this makes the girls' work lighter and the meals are ready on time...this also contributes to reducing the girls' work"

This is typical of how members of staff focus on the need for more physical help and, since the project could not afford to employ more people, the work and help of the volunteers is necessary. "Support" was a recurring theme in their responses, mainly through manual labour due the increasing numbers of children in the projects. Accordingly, Belinda adds that:

"[volunteers] come to help us, not only economically, but mainly with what they do [...] with what they do for example here in the kitchen or in the nursery. They make our work lighter - they don't do our work but help us to manage our work".

Beneficiaries of projects on the other hand are more outspoken about their dependency on VT to satisfy personal materialistic needs. They explain that volunteer tourists bring clothes or toys for their children "like those that my daughter is wearing!", Berta comments, adding that they are much nicer than the Peruvian clothes.

\section{Motivations}

Motivations for being involved in VT also differed across the three groups of informants, because motivations tend to be driven by perceived needs. While directors and members of staff keep their motivations on a professional level, beneficiaries are more prone to establishing closer relationships with volunteer tourists. Generally directors are motivated to host volunteer tourists because they represent both a financial and a material resource for the projects. Dalmiro, for example, states that

"Sometimes they [the children] also receive some material gift, a book, a pencil, donations are made to our institution on different levels: they are not always 100 or 1000 euros, many times it's just a reading book with less than half the pages in it!”.

Additionally, Doris says that:

"Volunteers are of big help for us [...] because of our financial circumstances [...]. We cannot afford to pay for other employees [...]".

Members of staff claim to need physical help and are motivated to assist volunteer tourists to make their own jobs easier. Mónica comments that: 
"They [the volunteers] help us quite a lot with the children. For example they help us not only when they [the children] are having dinner but also when they do their homework".

Because of their personal need for material, financial and affective help, beneficiaries are motivated to establish closer relationships (such as friendships or romances) with volunteer tourists in order to fulfil their own needs. Beatriz mentions that:

"A guy fell in love with a girl from here [project] ... I don't know if it happens frequently but we all knew that they fell in love...”.

Belinda meanwhile addresses the possibility of developing friendships with volunteers:

"With volunteers we can build a friendship which lasts for years [...]".

Friendship and intimate relationships in general are crucial aspects of the volunteer-resident encounter, especially in the beneficiaries' responses on needs and motivations; this aspect will be elaborated in more detail later in the paper as it acquires great importance through the application of ET.

\section{Expectations}

The expectations held by the stakeholders are the last aspect considered before moving on to assessing the inputs and outcomes. Usually directors and members of staff are less inclined to consider the leisure and recreational aspects of the VT experience. Directors repeatedly expressed the desire to have responsible and committed volunteers. Doris, for example, shows her disappointment with tourists who did not take their volunteer role seriously:

"[volunteers should] come [to the project] as if they were going to work. I don't know...many times they come only to have fun, to drink, to dance all the time! That's ok, but when they come here they have to be well-presented...”.

Beneficiaries have different expectations and try to create closer and perhaps longer lasting relationships with volunteer tourists as a response to their previously identified needs.

Brunilda says that:

"I've a friend called Maria, from Spain. She stayed here [at the shelter house] for six months [...]. I'm still in contact with here through Internet [...]. She asks me how's my baby [...]".

Beatriz also comments on her relationship with a former volunteer: 
"She [the volunteer] always remembers us [Beatriz and her son]! She also sent him a present for his birthday. I have to go and collect it [...]. She sends him a present every year but if there are other volunteers coming from Barcelona she asks them to bring it!”

In some cases, such continuity can guarantee support even once the volunteers return to their home country. Yet, although within the context of beneficiaries' responses the concept of time was related to a more personal and intimate dimension, for some members of staff and directors time was mainly associated with the volunteer tourists' quality of work. Manuel, for example, highlights that:

"in reality a month or less than a month is too short a time to assess volunteers' work or to see any change [in the project]".

Mateo adds that:

"it [the quality of work] depends on the volunteers: there are volunteers who stay for a long time and bring ideas [...] but if they come for a month it's impossible!”.

In other words, according to some, the longer the volunteer tourists stayed in the projects the better their work was likely to be.

\section{Inputs and outcomes}

\section{Frustration and resentment}

Directors perceive themselves as contributing a considerable amount of administrative work to host volunteer tourists, which can lead to disparities between their investments and those of their counterparts. They consider volunteer tourists' inputs to be lower than their own and often perceive them as passive and easily bored, and at times unwilling to work. Diana, for example, explains that:

"they [the volunteers] don't work hard! If I have to evaluate them I would say that $10 \%$ [of volunteers work] they don't stay for a long time. [...].

Doris complains that:

“There are many volunteers that come here [to the project] and don't want to do anything! [...] They just sit down and observe [...]"

This scenario may cause frustration and resentment. Therefore, according to ET, directors will seek either to restore equity and change their own inputs, or keep the situation unchanged but alter their behaviours towards volunteer tourists. Balance can be re-established through increasing the volunteer tourists' commitment to the project by proactively managing the recruitment. The perception of an imbalanced exchange between directors and volunteer tourists is also likely to arise if 
projects receive volunteers through a mediated process (e.g. foreign companies or Spanish language schools). Residents, and more specifically directors, do not feel in control of the flow and management of volunteer tourists and thus the exchanges are imbalanced, resulting in negative relationships.

\section{Benevolent feelings}

Members of staff generally express more benevolent attitudes than directors towards volunteer tourists' inputs, having had lower expectations in the first place of how many hours they will do or the quality of their work, and also seeing the volunteering projects instrumentally (i.e. as a means to earn a salary). Having said that, although members of staff usually value volunteer tourists' efforts the volunteer quality is varied and friction can rise from work imbalances. In many cases, for example, volunteers work fewer hours, as Bianca comments:

"Sometimes I feel it [frustration] because I work and the foreigners don't. Foreigners work for a few hours and they leave early [...] I would like to work like they do, for a few hours and go back and have a rest with my kids. In reality we [members of staff] work all day long”.

Additionally, for some, volunteers are passive and often challenge the project's rules, causing conflict between staff and beneficiaries, as Mariangeles describes:

"We cannot give any sweets [to the kids] before a meal and the volunteers - yes! - because they are always good and live just that moment. But we stay here every day and to us this makes a difference...several times the nurses were angry and came to me and said <they [the volunteers] come to ruin my work! >”.

Milagros reinforces Mariangeles’ words, saying that:

“There are some volunteers who don't help, they just observe [...]. We cannot force volunteers to work or look after the kids, we cannot. If something happens to the child the responsibility is mine."

Yet in general, inputs from members of staff are perceived to be more on an equal level and the outcomes meet their initial expectations. Hence, if they perceived receiving genuine help from volunteer tourists in turn perceived that the volunteers experience feelings of contentment from being helpful.

\section{Moving beyond materialities}

In the beneficiaries' responses there is more evidence of intentionally aiming for intimate relationships such as friendships or romances. Beneficiaries see themselves as inferior to volunteer tourists, resulting from stereotyping volunteers' lifestyles and socio-economic backgrounds, and volunteer tourists are generally perceived as occupying a comparatively privileged position. María 
observes that "the girls copy everything; from the way they [volunteers] dress to the way they talk [...]". Beneficiaries idealise the world that volunteers come from, Betina for example believes that "bad things could happen just here [in Peru]".

Beneficiaries' inputs often include copying behaviour and tastes, spending time together going out, and also getting pleasure from showing volunteers some of their own traditions (dancing or cooking), all of which helps restore some of the equal footing posited by ET. Beneficiaries of course are not homogeneous: the more extrovert or attractive ones tend to get more attention from volunteers - and more gifts - which creates jealousies. Begoña says that increasing the number of volunteer tourists has made relationships between the girls (beneficiaries) weaker and superficial, and that they are less selfreliant and more prepared to be dependent.

An important theme running across all these interactions is the identification of geographically defined and socially constructed spaces where destination stakeholders and volunteers meet. Notably, interactive dynamics often develop within the residents' private spaces. Because of this, the inevitable theme of intrusiveness has been discussed by some as an undesired outcome. Manuel comments on this and says that:

"We started to live together in the same place, with the volunteer [...] and at some point the relationship became invasive and I started to have problems with the volunteers [...]. Now [...] the relationship is good but in general I don't have close relationships because the contact is related just to work".

In some cases, attempts are made to restore a more balanced relationship as, by exchanging fewer inputs than before in order to restore equity. In other situations, volunteer tourists' presence has been restricted to some areas of the project or the stakeholders' lives to limit intrusiveness. For example, in the shelter house, volunteer tourists are given access only to the nursery or the kitchen apart from exceptional circumstances, as Mateo specifies:

"the space that we offer to volunteers here [at the project] is limited and well defined".

Stakeholders who feel vulnerable because their intimate spaces are invaded tend to create some neutral spaces where interactions take place.

\section{Discussion}

Among the three destination stakeholder groups, the results show that beneficiaries and members of staff are more likely to develop positive perceptions of their encounters with volunteer tourists because of perceived balanced exchanges. In general, stakeholders who feel in an unfair exchange are often not in control of volunteers or volunteering actions within their private spaces (e.g. a project or 
someone's house). The whole VT experience, therefore, instead of fostering destination empowerment as commercially claimed, has the potential to exclude stakeholders from the decisionmaking process. This unavoidably generates negative perceptions in those stakeholders who deal with volunteers but who cannot control them. Usually directors decide whether or not their projects could receive volunteers but, in many cases, they do not have the necessary tools or links to access volunteer tourists directly and they only partly control the process (e.g. limiting which areas or tasks of the projects are accessible to volunteers), while feeling exploited by the mediators.

Imbalances are perceived also because of the lack of commitment and expertise of volunteers, which causes frustration in residents who devote their time and effort to look after them. Yet whilst the work that volunteer tourists do is for many not essential, Cusqueños argue that they still need their support. Thus, informants mentioned on some occasions that they prefer an imbalanced situation to receiving nothing. In this context frictions between donors and residents emerge and the behaviours of participants are altered as a response to inequity (i.e. anger towards volunteers; ignoring their presence in the project, etc.).

Some informants mention short-term tangible material and financial contributions by the volunteer tourists, but none of them comment on long-term impacts. The increased capacity of volunteering projects has somehow created an opportunity to outsource parental responsibilities, as children will be looked after by a treadmill of changing foreign faces, increasing VT dependency. Higher demand for and supply of VT experiences shows the increased commercialisation of the sector where local needs are often constructed and promoted following homogeneous, simplified and romanticised imaginaries to attract tourists. In some cases, VT brings residents to rely solely on the contributions of foreigners, assuming that this is part of the natural process of being involved in VT. This study demonstrates that in spite of the episodic and short-term nature of VT (Guttentag, 2009; Tomazos and Cooper, 2012; Vodopivec and Jaffe, 2011), its impacts on residents and their social structures are longer lasting.

Furthermore, the generosity and help of volunteer tourists make some stakeholders feel that they are in an unbalanced relationship. This happens, for example, to beneficiaries who, in order to reciprocate, are more willing to develop affectionate feelings for volunteer tourists and build longlasting relationships with them (e.g. romances and friendships). In some cases, however, stakeholders do not feel in a position to reciprocate and restore equity because volunteers are considered wealthier and more advantaged. The findings revealed that in this scenario, stakeholders do not evidence any interest in getting closer to volunteers or in developing further relationships. ET postulates that within helping relationships, the ability to repay affects the donor-recipient encounter. The material help of volunteer tourists is therefore repaid with positive behaviours of recipients. 
The findings also reveal that the socio-economic position of the respondents and their level of education are determinants in affecting their opinions. This meant that informants without direct access to tourists were more likely to present images of volunteer tourists which do not correspond to reality. Stakeholders who do not themselves make the choice to come into contact with volunteer tourists (e.g. members of staff in volunteering projects; beneficiaries) filter their perceptions according to what had been presented by others or shown by the tourists.

A further finding is that in general, individuals with direct connections to tourism are more predisposed to accept tourism development. This finding confirms previous theories according to which residents who are involved in the business are more likely to be supportive of it than those who do not actively participate (Andereck et al, 2005; Williams and Lawson, 2001). In addition, stakeholders who are able to choose the degree and type of their involvement in the industry demonstrated more positive feelings than those who had no control over the process. This last aspect received particular attention because tourism in Cusco (as discussed for VT) is a highly mediated process with local and international organisations, charities, NGOs and Spanish schools acting as intermediaries between destination stakeholders and volunteers.

Similarly, inequalities are perceived to affect the VT business. The unequal distribution of material resources, the unequal social positions of stakeholders and the unequal exposure to volunteers exacerbate conflicts within the local population. Therefore, although it is argued that VT "serves as a stronghold for the privileged” (McGehee, 2012: 10) in addressing the power relations between volunteers and residents, this research also addresses the hostile situations which VT can create among residents. As a result of the high demand for VT experiences in Cusco, the number of volunteering projects and hosting families are growing and this contributes to intensify, as Simpson (2005) claims in her study, local competition and resentment.

This reconsideration of VT, however, still leaves space to acknowledge its perceived positive impacts, particularly in reciprocal relationships. Perceived equity allows reframing VT encounters within notions of care and affection. In Cusco the cultural exchange between destination stakeholders and volunteer tourists fosters the development of balanced exchanges and, consequently, of positive perceptions. Thus, VT has the potential to foster mutual understanding among cultures as Conran (2011) highlights in her study. On a similar positive note, Sin (2009) underlines the socio-cultural implications that VT encounters can have for the individuals involved. This explains the dynamism in VT encounters as, although its monetary and materialistic aspects are acknowledged as influential in the formation of some relationships, VT strengthens and allows the emergence of deeper bonds between residents and volunteer tourists, but not always in the ways that would have been expected a priori. 
As demonstrated in this paper, the use of ET to analyse micro-levels of interactions and encounters within VT adds to our understanding of the socio-cultural aspects of tourism. The analysis of these interactions moves beyond the economic aspects of the exchange as the economic dimension of VT cannot be separated from more intangible concepts such as friendship or affection. The dynamism and fluctuations between these two dimensions are disclosed by the attempts to restore equity and create a perception of balanced encounters.

\section{Conclusions}

This study adopted ET to investigate destination stakeholders' perceptions of VT with a focus on the dynamics behind stakeholder-volunteer encounters. Through the application of ET the authors sought to examine why and how stakeholders interact with volunteers through the investment and distribution of various resources. The analysis focused first on the evaluation of perceived needs, motivations and expectations of the stakeholders and then compared inputs and outcomes in order to explore why they developed certain feelings toward volunteer tourists (e.g. frustration, anger, satisfaction, affection, care). The monetary and materialistic aspects which are often part of VT are acknowledged as influential in some relationships and encounters, but this investigation moves beyond materialism as the only relevant factor that affects these encounters through the use of ET, which is one of its main contributions.

The model has contributed to an understanding of why (and whether) three key stakeholder groups in Cusco are reluctant to deal with volunteer tourists or, conversely, why they are prone to develop relationships with them. ET proved to be a relevant conceptual framework to understand VT social interactions and the complexities, ambiguities, heterogeneity and dynamism of human relations in a tourism context. The complexities and multitude of perceptions held by stakeholders have been untangled through the application of ET which helped to understand how individuals relate to each other within the asymmetric scenario of volunteer tourism.

Nevertheless, although the application of ET to complex social contexts proved to have the potential to uncover important findings, an open stance of interpretation has to be kept throughout for a more inclusive analysis of VT. Human interactions and exchanges are comprised of complex patterns which cannot be always schematically defined. Therefore, we argued that a dynamic and open approach to analysing and discussing stakeholder-volunteer encounters is necessary without relying only on a theoretical path for interpretation. Bearing this in mind, it is argued that while on the one hand the conceptual framework helped to draw generalisations, on the other hand, the same model could have constrained the interpretation of the data to mere categories if other contextual factors (e.g. social, cultural and geographical backgrounds) were not considered. Thus, future research on residents' perceptions of VT should involve the application of ET to other stakeholders (i.e. volunteer 
tourists; meditators) and under different socio-economic and geographical contexts. This could allow the strengthening and modifying of ET for a more flexible approach to VT studies.

To conclude, the application of ET allowed achieving a better understanding of the dynamism which moves and characterises VT and of the nexus between the materialistic and affective elements of the industry. For the first time the theory has been applied to analyse the interactive processes in stakeholder-volunteer encounters. This can have valuable implications for the management of the VT industry in facilitating more equitable exchanges and fairer degrees of participation among local populations.

\section{References}

ADAMS, J. S. 1963. Towards an understanding of inequity. Journal of Abnormal and Social Psychology, 67 (5), pp. 422-436.

ANDERECK, L., VALENTINE, K., KNOPF, R. \& VOGT, C. 2005. Residents' perceptions of community tourism impacts. Annals of Tourism Research, 32, pp. 1056-1076

BROAD, S. 2003. Living the Thai life-a case study of volunteer tourism at the Gibbon Rehabilitation Project, Thailand. Tourism Recreation Research, 28, 63-72.

BROWN, S. 2005. Travelling with a purpose: Understanding the motives and benefits of volunteer vacationers. Current Issues in Tourism, 8, 479-496.

BROWN, S. \& LEHTO, X. 2005. Travelling with a purpose: understanding the motives and benefits of volunteer vacationers. Current Issues in Tourism, 8 (6), pp. 479-496.

CALLANAN, M. \& THOMAS, S. 2005. Deconstructing volunteer activities within a dynamic environment. In: Novelli, M. ed. Niche Tourism, Oxford, Elsevier, Butterworth and Heinemann, pp. 183-200.

CHANG, J. C. 2008. Tourists' satisfaction judgments: An investigation of emotion, equity, and attribution. Journal of Hospitality \& Tourism Research, 32, 108-134.

CHEN, L.-J. \& CHEN, J. S. 2011. The motivations and expectations of international volunteer tourists: A case study of "Chinese Village Traditions". Tourism Management, 32, 435-442.

COGHLAN, A. 2005. Towards an understanding of the volunteer tourism experience $\mathrm{PhD}$, James Cook University.

COGHLAN, A. 2007. Towards an integrated image-based typology of volunteer tourism organisations. Journal of sustainable tourism, 15, 267-287.

COHEN, E. 1984. The sociology of tourism: approaches, issues, and findings. Annual review of sociology, 373-392.

CONRAN, M. 2011. 'They really love me!' Intimacy in volunteer tourism. Annals of Tourism Research, 38 (4), pp. 1454-1473.

CROUCH, D. 2000. Places around us: embodied lay geographies in leisure and tourism. Leisure Studies, 19, 63-76.

CROUCH, D. \& DESFORGES, L. 2003. The Sensuous in the Tourist Encounter Introduction: The Power of the Body in Tourist Studies. Tourist Studies, 3, 5-22.

EMBERSON, M. 2002. The equity theory of motivation: an ethnographic case study of a voluntary sector organisation. University of Kent at Canterbury.

GOODWIN, H. 2011. Taking responsibility for tourism, Goodfellow Publishers.

GUTTENTAG, D. A. 2009. The possible negative impacts of volunteer tourism. International Journal of Tourism Research, 11, 537-551.

HALPENNY, E. A. \& CAISSIE, L. 2003. Volunteering on nature conservation projects: volunteer experience, attitudes and values. Tourism Recreation Research, 28, 25-33. 
HANNAM, K., SHELLER, M. \& URRY, J. 2006. Editorial: Mobilities, immobilities and moorings. Mobilities, 1, 1-22.

HATFIELD, E. \& SPRECHER, S. 1983. Equity theory and recipient reactions to aid. New directions in helping, 1, 113-141.

HATFIELD, E., UTNE, M.K., \& TRAUPMANN, J. 1979. 'Equity theory and intimate relationships.' In R. Burgess and T.L. Huston (eds), Social Exchange in Developing Relationships, Academic Press, New York.

HIGGINS-DESBIOLLES, F. \& RUSSELL-MUNDINE, G. 2008. Absences in the volunteer tourism phenomenon: the right to travel, solidarity tours, and transformation beyond the one-way. In: Lyons, K. and Wearing, S. eds. Journeys of discovery in volunteer tourism, CABI Publications, Wallingford, pp. 182-19.

LINCOLN, Y.S. \& Guba, E.G., 1985 Naturalistic inquiry, SAGE Publications, California

LEPP, A. 2008. Attitudes towards initial tourism development in a community with no prior tourism experience: the case of Bigodi, Uganda. Journal of Sustainable Tourism, 16 (1), pp. 5-22.

LO, A. S. \& LEE, C. 2011. Motivations and perceived value of volunteer tourists from Hong Kong. Tourism Management, 32, 326-334.

MCGEHEE, N.G. 2002. Alternative tourism and social movements. Annals of Tourism Research, 29 (1), pp. 124-143.

MCGEHEE, N.G. 2012. Oppression, emancipation, and volunteer tourism: Research propositions. Annals of Tourism Research, 39 (1), 84-107.

MCGEHEE, N. G. \& ANDERECK, K. 2009. Volunteer tourism and the "voluntoured": the case of Tijuana, Mexico. Journal of Sustainable Tourism, 17 (1), pp. 39-51.

MCGEHEE, N.G., ANDERECK, K., LYONS, K. \& WEARING, S. 2007. 'Pettin'the critters': exploring the complex relationship between volunteers and the voluntoured in McDowell County, West Virginia, USA, and Tijuana, Mexico. Journeys of discovery in volunteer tourism: International case study perspectives, 12-24.

MCGEHEE, N.G. \& NORMAN, W.C. 2002. Alternative tourism as impetus for consciousnessraising. Tourism Analysis, 6, pp. 239-251.

MCGEHEE, N.G. \& SANTOS, C.A. 2005. Social change, discourse and volunteer tourism. Annals of Tourism Research, 32 (3), pp. 760-779.

MCINTOSH, A.J. \& ZAHRA, A. 2007. A cultural encounter through volunteer tourism: Towards the ideals of sustainable tourism?. Journal of Sustainable Tourism, 15 (5), pp. 541-556.

MOSTAFANEZHAD, M. 2013. The politics of aesthetics in volunteer tourism. Annals of Tourism Research, 43, pp. 150-169.

NASH, D. 1989. Tourism as a form of imperialism. Hosts and guests: The anthropology of tourism, 2, 37-52.

PALACIOS, C. M. 2010. Volunteer tourism, development and education in a postcolonial world: conceiving global connections beyond aid. Journal of sustainable tourism, 18, 861-878.

PEARCE, P. \& COGHLAN, A. 2008. The dynamics behind volunteer tourism. Journeys of Discovery in Volunteer Tourism-International Case Study Perspectives, Wallingford, 130-143.

PEARCE, P. L., MOSCARDO, G. \& ROSS, G. F. 1991. Tourism impact and community perception: An equity-social representational perspective. Australian Psychologist, 26, 147-152.

PERDUE, R. R., LONG, P. T. \& ALLEN, L. 1990. Resident support for tourism development. Annals of Tourism Research, 17, 586-599.

RAYMOND, E. M. \& HALL, C. M. 2008. The development of cross-cultural (mis) understanding through volunteer tourism. Journal of sustainable tourism, 16, 530-543.

SALDAÑA, J. 2009. The coding manual for qualitative researchers, London, SAGE Publications.

SIMPSON, K. 2004. 'Doing development': The gap year, volunteer-tourists and a popular practice of development. Journal of International Development, 16, 681-692.

SIMPSON, K. 2005. Dropping out or signing up? The professionalisation of youth travel. Antipode, 37, 447-469.

SIN, H. L. 2009. VOLUNTEER TOURISM-“INVOLVE ME AND I WILL LEARN”? Annals of Tourism Research, 36, 480-501.

SIN, H. L. 2010. Who are we responsible to? Locals' tales of volunteer tourism. Geoforum, 41, 983992. 
TOMAZOS, K. \& BUTLER, R. 2010 The volunteer tourist as 'hero'. Current Issues in Tourism, 13 (4), pp. 363-380

TOMAZOS, K. \& COOPER, W. 2012. Volunteer tourism: at the crossroads of commercialisation and service? Current Issues in Tourism, 15, 405-423.

VAN DEN BERGHE, P. L. 1980. Tourism as ethnic relations: A case study of Cuzco, Peru. Ethnic and Racial Studies, 3, 375-392.

VODOPIVEC, B. \& JAFFE, R. 2011. Save the world in a week: Volunteer tourism, development and difference. European Journal of Development Research, 23, 111-128.

WALSTER, E., BERSCHEID, E. \& WALSTER, G. W. 1973. New directions in equity research. Journal of personality and social psychology, 25, 151.

WEARING, S. 2001. Volunteer tourism: Experiences that make a difference, Cabi.

WEARING, S. \& MCGEHEE, N.G. 2013. Volunteer tourism: a review. Tourism Management, 38, pp. 120-130.

WILLIAMS, J. \& LAWSON, R. 2001. Community issues and resident opinions of tourism. Annals of Tourism Research, 28 (2), pp. 269-290 